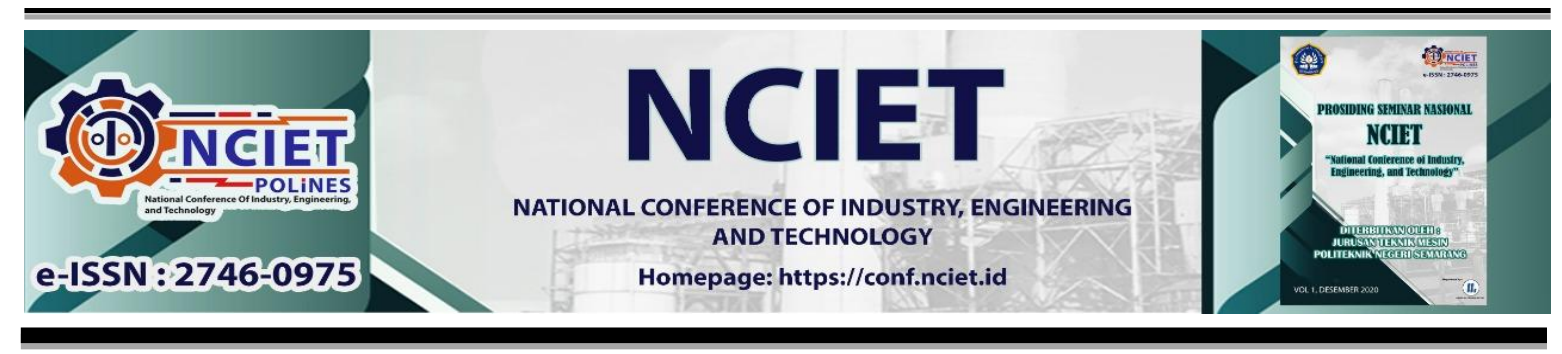

Prosiding Seminar Nasional NCIET Vol.1 (2020) B277-B285

$1^{\text {st }}$ National Conference of Industry, Engineering and Technology 2020,

Semarang, Indonesia.

\title{
APLIKASI HUKUM BERNOULLI PADA ALAT PERAGA FLOW METER UNTUK PRAKTIKUM MEKANIKA FLUIDA
}

\author{
Qoriatul Fitriyah*, Albertus Agung Dananto Setyawan, M. Prihadi Eko W \\ Jurusan Teknik Elektro, Politeknik Negeri Batam \\ Jl. Ahmad Yani Batam Kota. Kota Batam. Kepulauan Riau, 29461 \\ *E-mail: fitriyah@ polibatam.ac.id
}

\begin{abstract}
Abstrak
Hukum Bernoulli merupakan dasar yang dipelajari dalam mata kuliah Mekanika Fluida. Hukum ini menjelaskan bahwa fluida yang bergerak lebih cepat akan menghasilkan lebih sedikit tekanan, dan sebaliknya, fluida bergerak lebih lambat akan menghasilkan tekanan yang lebih besar. Selama ini, mahasiswa cenderung mengalami kesulitan dalam memahami materi yang disampaikan ditambah dengan banyaknya persamaan yang harus dihitung terutama dalam kaitannya dengan persamaan Bernoulli. Alat peraga flow meter didesain untuk memenuhi kebutuhan akan media pembelajaran aplikatif yang bisa diimplementasikan khususnya pada mata kuliah Mekanika Fluida, salah satunya untuk mendorong terbentuknya pola pikir kritis pada mahasiswa.
\end{abstract}

Kata Kunci: Mekanika Fluida; Bernoulli; Hukum Bernoulli; Media Pembelajaran; Alat Peraga; Flow Meter; Praktikum Mekanika Fluida

\section{PENDAHULUAN}

\section{Hukum bernoulli}

Daniel Bernoulli (1700 - 1782) adalah seorang ilmuwan kelahiran Belanda yang menuntut ilmu di Italia dan akhirnya menetap di Swiss. Lahir dari keluarga ahli matematika terkenal, ayahnya, Johann Bernoulli, adalah salah satu pengembang awal ilmu kalkulus dan pamannya Jacob Bernoulli, adalah yang pertama kali menemukan teori probabilitas [1].

Pada tahun 1724, dia menerbitkan buku latihan Matematika, dan pada 1725 dia merancang jam pasir yang membuatnya memenangkan hadiah Akademi Paris. Sebagai hasil dari ketenarannya yang semakin meningkat dalam bidang matematika, Daniel diundang ke St Petersburg untuk melanjutkan penelitiannya. Di sana dia menulis "Hydrodynamica", karya tulis yang paling masyhur hingga berabad-abad kemudian [1]. 
"Hydrodynamica", menjelaskan mengenai dinamika fluida, atau studi tentang bagaimana cairan berperilaku saat mereka sedang bergerak. Udara, seperti air, adalah fluida; Namun, tidak seperti air, yang merupakan cairan, udara adalah gas. Udara dianggap fluida karena mengalir dan dapat mengambil bentuk yang berbeda. Bernoulli menegaskan dalam buku "Hydrodynamica" bahwa fluida yang bergerak lebih cepat akan menghasilkan lebih sedikit tekanan, dan sebaliknya, fluida bergerak lebih lambat akan menghasilkan tekanan yang lebih besar [1].

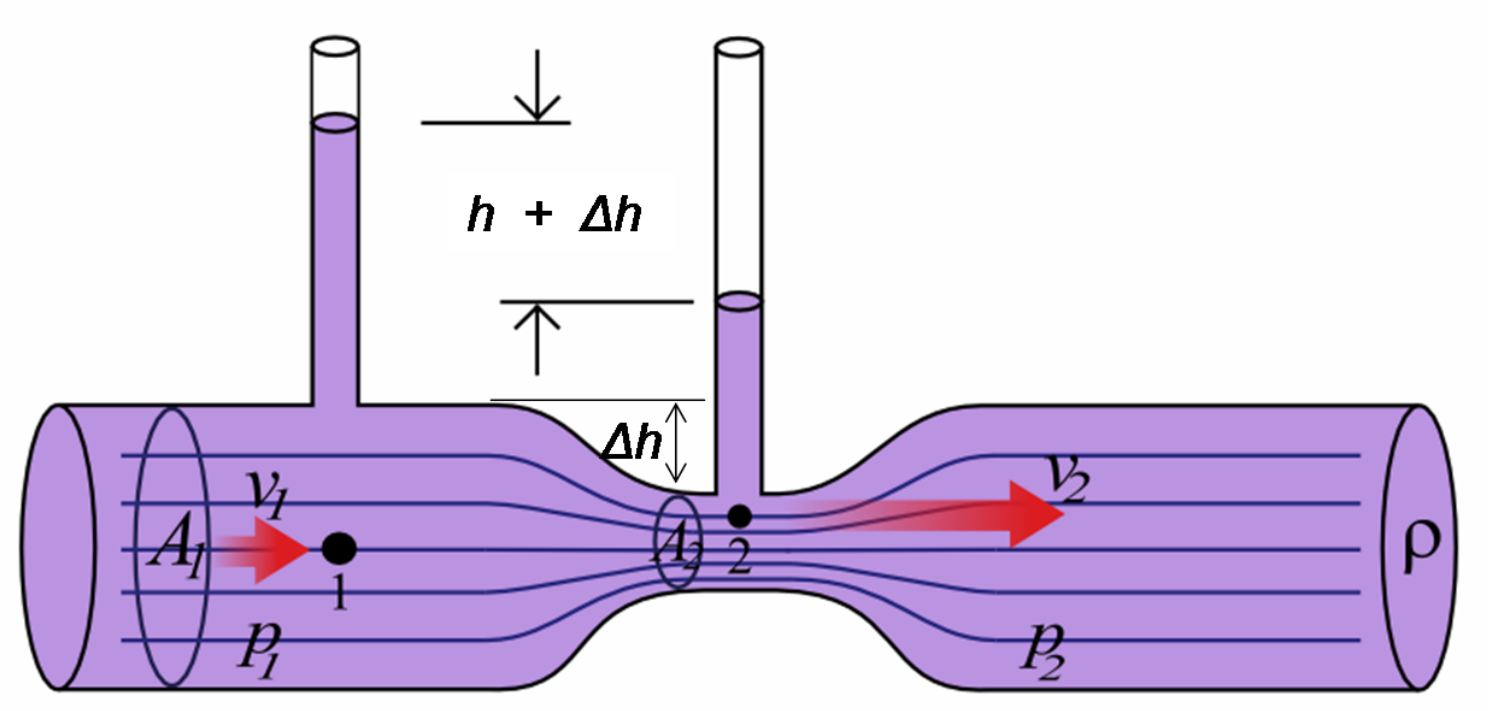

Gambar 1. Eksperimen Fluida Bernoulli [2]

Secara singkat, persamaan Bernoulli bisa dirumuskan sebagai berikut:

$$
P_{1}+\frac{1}{2} \rho v_{1}^{2}+\rho g h_{1}=P_{2}+\frac{1}{2} \rho v_{2}^{2}+\rho g h_{2}
$$

Persamaan 1. Bernoulli Equation [3]

Dimana:

$\mathrm{P}$ adalah tekanan (Pascal)

$\rho$ adalah massa jenis fluida $\left(\mathrm{kg} / \mathrm{m}^{3}\right)$

$\mathrm{v}$ adalah kecepatan fluida $(\mathrm{m} / \mathrm{s})$

g adalah percepatan gravitasi bumi $\left(9,807 \mathrm{~m} / \mathrm{s}^{2}\right)$

$\mathrm{h}$ adalah ketinggian $(\mathrm{m})$

\section{Media pembelajaran pada mata kuliah mekanika fluida}

Menurut Ramadhan [4], proses pembelajaran pada mata kuliah Mekanika Fluida tidak cukup hanya dengan metode ceramah saja. Mahasiswa cenderung mengalami kesulitan dalam memahami materi yang disampaikan ditambah dengan banyaknya persamaan yang harus dihitung terutama dalam kaitannya dengan persamaan Bernoulli. Oleh karena itu, 
Ramadhan berkesimpulan dibutuhkan tambahan media pembelajaran untuk menunjang penerapan teori kepada mahasiswa agar mahasiswa bisa memahami dan mengaplikasikan mata kuliah Mekanika Fluida dengan lebih baik. Media pembelajaran diharapkan tidak saja menjadi supporting tools bagi dosen pengajar, akan tetapi dapat membawa informasi dan menjembatani pengetahuan (transfer knowledge) yang dibutuhkan oleh mahasiswa untuk mengerti esensi dari materi kuliah tersebut.

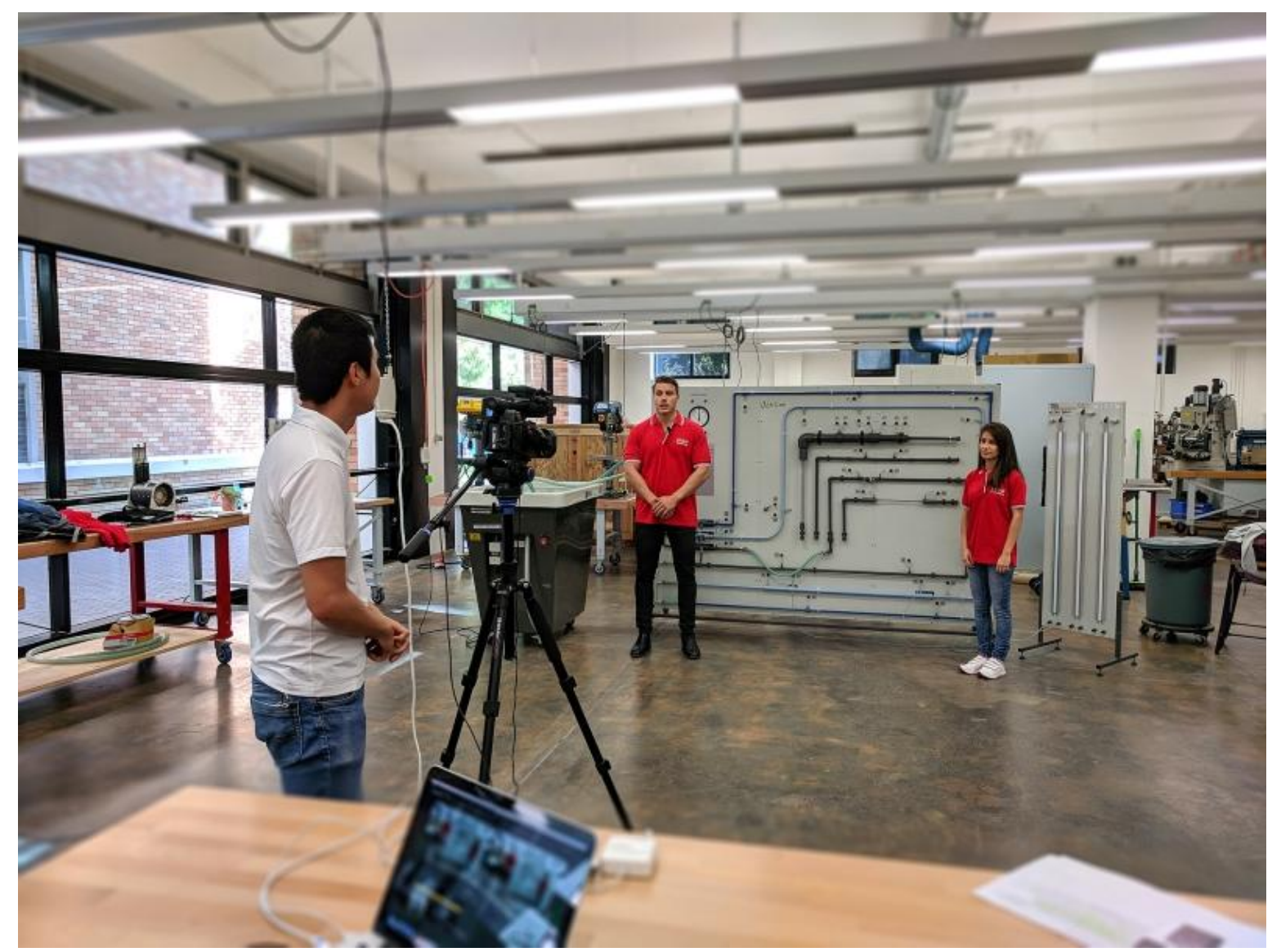

Gambar 2. Ilustrasi Media Pembelajaran pada Mata Kuliah Mekanika Fluida [5]

\section{Media pembelajaran}

Menurut Kosasih (2007:10), media pembelajaran cenderung diartikan sebagai alat-alat grafis, fotografis atau elektronis untuk menangkap, menyusun, memproses, dan menyusun kembali informasi visual atau verbal. Media juga dapat diartikan sebagai segala sesuatu yang dapat dipergunakan untuk menyalurkan pesan, merangsang pikiran, perasaan, perhatian, dan kemauan siswa, sehingga dapat terdorong terlibat dalam proses pembelajaran [6].

Adapun tahapan belajar bisa diilustrasikan dengan kerucut pengalaman sebagai berikut: 


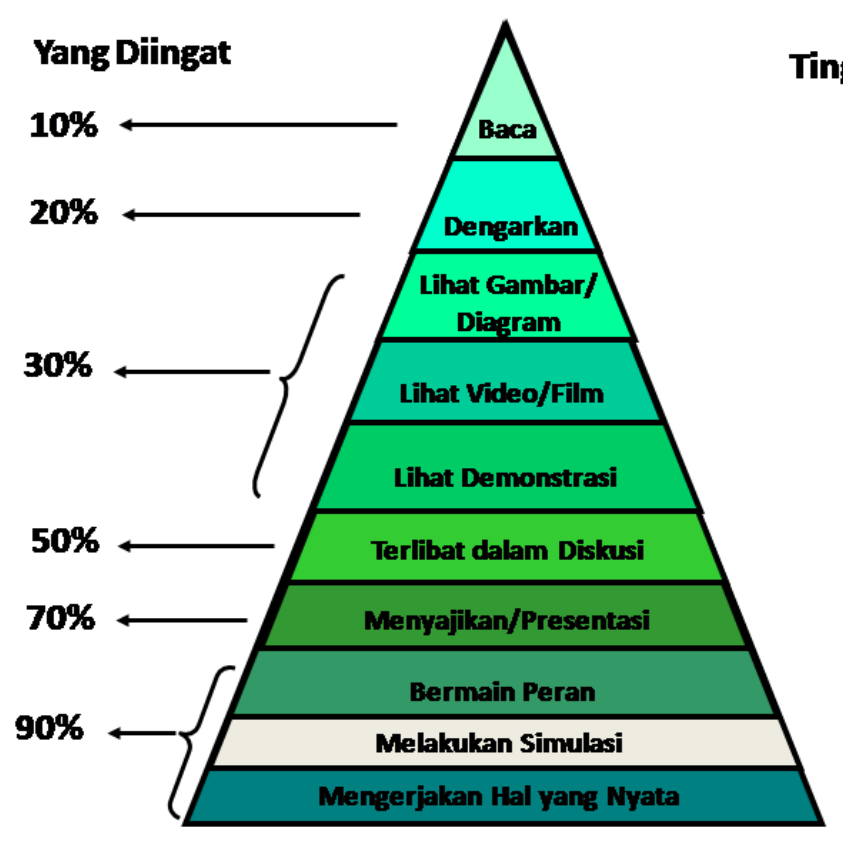

Tingkat Keterlibatan

Gambar 3. Kerucut pengalaman [7]

Semakin ke atas, semakin kecil kegiatan tersebut berimplikasi pada mahasiswa, yang berarti bahwa semakin sedikit pengetahuan yang diingat dan diserap [8]. Dari kerucut tersebut juga bisa diketahui bahwa dengan melakukan simulasi atau percobaan, tingkat keterserapan materi bisa mencapai $90 \%$.

\section{Pengembangan keterampilan berpikir kritis melalui praktikum}

Menurut penelitian yang telah dilakukan oleh Kurniawan [9], diperoleh data bahwa model pembelajaran Mekanika Fluida yang hanya dilakukan dengan metode ceramah tanpa adanya praktikum menyebabkan mahasiswa mengalami kesulitan dalam memahami konsep mekanika yang memerlukan bukan hanya hitungan, namun juga visualisasi alat serta aplikasi mata kuliah. Keterampilan berfikir kritis merupakan salah satu bentuk keterampilan yang memerlukan brain processing yang cukup tinggi. Kemampuan berpikir kritis menuntut penggunanya bisa menyelesaikan masalah atau yang disebut sebagai problem solving.

Mahasiswa membutuhkan stimulasi yang terus-menerus agar daya nalar kemampuan berpikir kritisnya bisa semakin berkembang. Dalam perkuliahan, kemampuan ini termasuk mendeteksi hal yang relevan, menjabarkan materi pelajaran, kemampuan reasoning dari eksprimen yang dilakukan, memberikan definisi dari materi pelajaran yang diberikan, membuat laporan ilmiah, pertimbangan mengenai prosedur dengan meminimalisir faktor dugaan dan perasaan dalam setiap percobaan yang dikerjakan. 


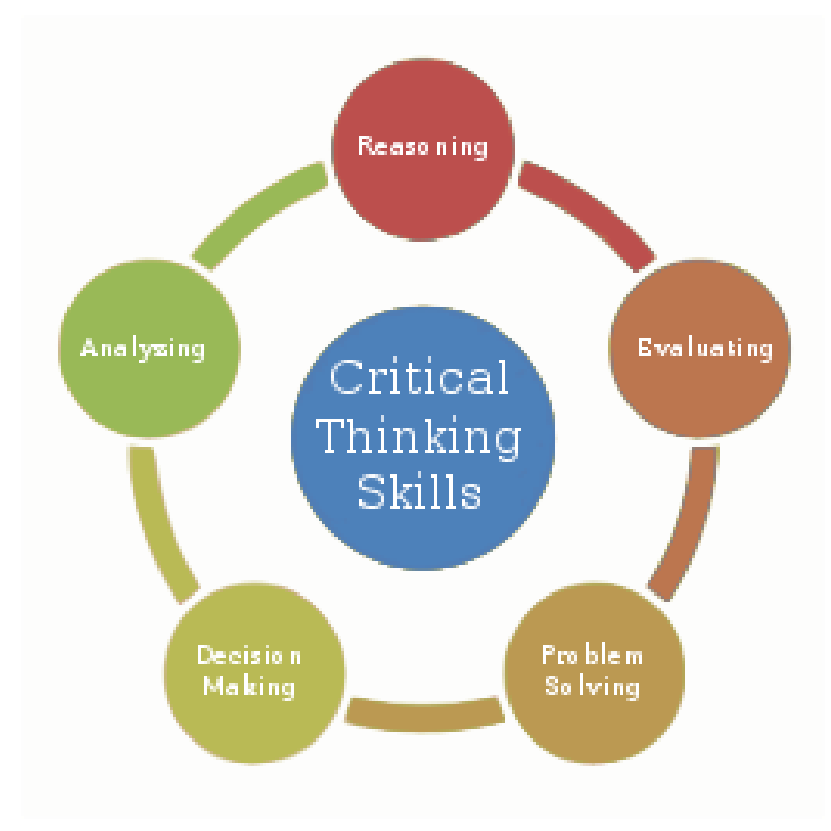

Gambar 4. Diagram Keterampilan Berpikir Kritis [10]

\section{METODE PENELITIAN}

Flow meter merupakan alat peraga yang dibuat secara customized untuk menyediakan media pembelajaran yang memadai dalam mata kuliah Mekanika Fluida untuk aplikasi dalam penerapan hukum Bernoulli. Secara umum, alat ini akan menghitung dan menampilkan tekanan serta debit aliran fluida.

Alat akan dimulai dengan pengecekan kondisi air pada tangki penampungan. Fluida yang digunakan adalah air karena murah, perawatannya rendah serta tidak memerlukan perbedaan tekanan yang terlalu besar. Setelah itu, pompa akan mulai dinyalakan. Apabila pompa tidak menyala, maka pengecekan pada tempat penampungan air harus dilakukan kembali, dan apabila pompa menyala, maka air selaku fluida akan mulai mengalir dan melewati rotameter sekaligus pressure meter. Data pengukuran yang ditampilkan kemudian dicatat mahasiswa untuk dianalisis lebih lanjut tergantung kebutuhan dalam kegiatan belajar mengajar yang akan dilakukan. 


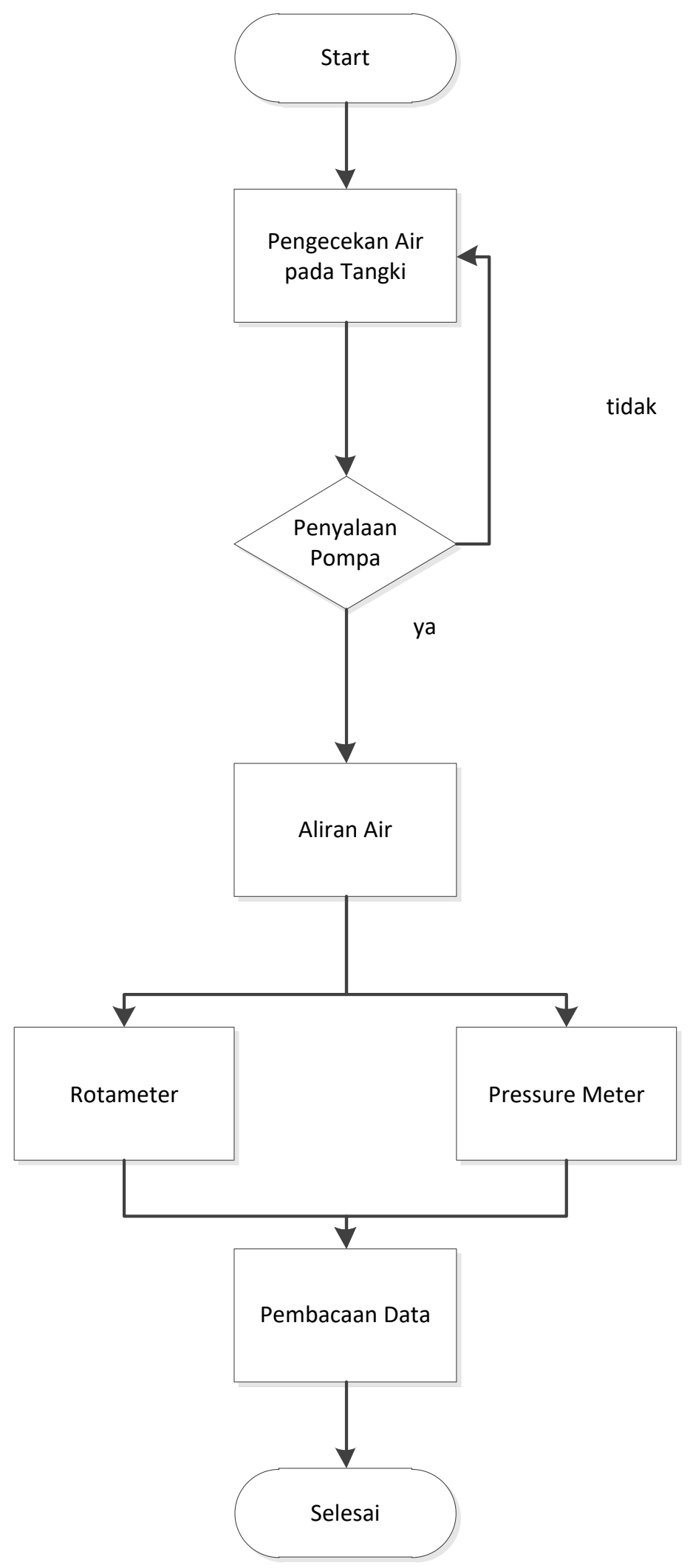

Gambar 5. Diagram alir Alat Peraga Flow Meter 


\section{HASIL DAN PEMBAHASAN}

Hasil perancangan mekanik dari flow meter dapat dilihat pada gambar berikut ini:

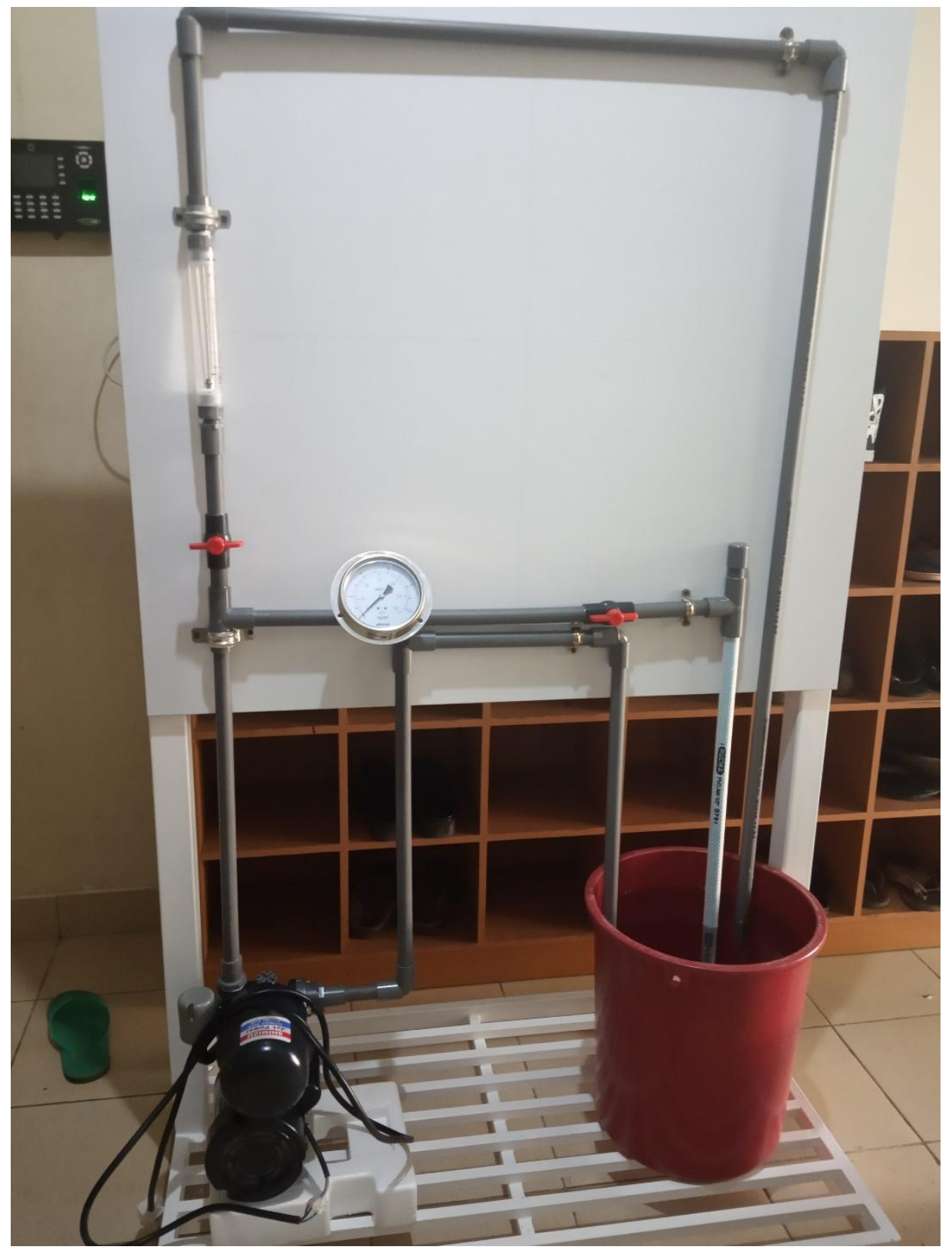

Gambar 6. Hasil Rancang Bangun Mekanik dari Alat Peraga Flow Meter

Alat ini terdiri dari beberapa bagian yaitu pompa air AC otomatis, tangki air yang sementara diganti dengan ember agar mudah dalam melakukan mobilisasi alat, alat pembaca tekanan (pressure meter), rotameter air, serta beberapa valve manual yang digunakan untuk membuka tutup aliran air apabila diperlukan. 
Tabel 1. Contoh Hasil Pengukuran yang Didapatkan dari Alat Peraga Flow Meter

\begin{tabular}{|c|c|}
\hline $\mathbf{P}\left(\mathbf{k g} / \mathbf{c m}^{2}\right)$ & $\mathbf{V}(\mathbf{l p m})$ \\
\hline 1 & 1.8 \\
\hline 1.2 & 3 \\
\hline 1.4 & 6 \\
\hline 1.4 & 9 \\
\hline 1.4 & 12 \\
\hline 1.4 & 15 \\
\hline 1.4 & 18 \\
\hline
\end{tabular}

Contoh data tersebut bisa diolah dan dibahas lebih lanjut oleh mahasiswa sebagai bahan untuk menghitung aplikasi Bernoulli, korelasi antara tekanan dan debit air, analisis kecepatan fluida, bahkan dari yang paling sederhana yaitu konversi besaran dari besaran non SI menjadi besaran baku sesuai dengan kaidah SI.

\section{KESIMPULAN}

Pemantapan teorema hokum Bernoulli bisa dilakukan melalui penerapan media pembelajaran, salah satunya melalui alat peraga flow meter di samping pemberian materi kuliah yang berupa teori. Hal ini dilakukan agar pembelajaran lebih dinamis, mudah diserap dan diikuti serta melatih pembentukan pola pikir kritis mahasiswa terutama dalam aplikasi mata kuliah Mekanika Fluida.

\section{DAFTAR PUSTAKA}

[1]. NASA, Bernoulli's Principle. 2010.

[2]. HappyApple, Diagram illustrating the Venturi effect, in https://upload.wikimedia.org/wikipedia/commons/thumb/4/4b/Venturi5.svg/579px -Venturi5.svg.png.

[3]. Ibadurrahman, Hukum Bernoulli, in https://s0.wp.com/latex.php?latex $=P \quad 1+\% 2 B+\% 5$ Cfrac\%7B1\%7D\%7B2\%7D+ $\% 5 C r h o+v \_1 \% 5 E 2+\% 2 B+\% 5 C r h o+g+h \_1+\% 3 D+P \_2+\% 2 B+\% 5 C f r a c \% 7 B 1$ $\% 7 D \% 7 B 2 \% 7 D+\% 5 C r h o+v \_2 \% 5 E 2+\% 2 B+\% 5 C r h o+g+h \_2 \& b g=f 9 f 9 f 9 \& f g=0$ $00000 \& s=0 \& c=20201002$.

[4]. Yosi Ramadhan, R., Wirawan Sumbodo, PENGEMBANGAN MEDIA PEMBELAJARAN PENGUKURAN RUGI ALIRAN FLUIDA CAIR DALAM PIPA VENTURI UNTUK MENUNJANG PERKULIAHAN MEKANIKA FLUIDA. Journal of Mechanical Engineering Learning, 2014. 
[5]. UNSW, Instructional videos created for fluid mechanics course, in http://www.wrl.unsw.edu.au/sites/wrl/files/uploads/News/2018\%20Tom\%20and\% 20Laura\%20filming\%20fluid\%20mechanics\%201.jpg. 2018.

[6]. Kosasih, R.A.d.A., Optimalisasi Media Pembelajaran. 2007: Gramedia Widiasarana.

[7]. Dale, E., Audio-Visual Methods in Teaching. 1969, New York: Rinehart \& Winston.

[8]. M.Pd., D.D. Media Pembelajaran. 2017.

[9]. Dede Trie Kurniawan, N.M.r.S., Nurul Ikhsan Kharimah, Pembelajaran Konsep Mekanika Fluida Statis Berbantuan Praktikum Virtual dalam Mengembangkan Keterampilan Berpikir Kritis Mahasiswa Calon Guru Matematika. JURNAL PHENOMENON, 2017. 7(2): p. 110-118.

[10].Zenhaus, Identifies skills required for critical thinking including reasoning, analyzing and problem solving, in https://upload.wikimedia.org/wikipedia/commons/thumb/2/20/Critical_Thinking_ Skills_Diagram.svg/275px-Critical_Thinking_Skills_Diagram.svg.png. 2018. 